\title{
A Controlled Atmosphere Chamber
}

\author{
Charles L. Gordon and Rolf B. Johannesen
}

\begin{abstract}
(February 12, 1963)
An inert atmosphere chamber for the transfer of reactive materials is described. It has the advantages of being inexpensive, easily cleaned, and can be evacuated.
\end{abstract}

\section{Introduction}

Many chemical compounds must be kept under an inert atmosphere while being transferred or sampled. Descriptions of a number of different inertatmosphere transfer chambers or so-called dry-boxes have been published. These can be classed in three types. The simplest is the inexpensive transfer chamber maintaining protection from the ordinary atmosphere by a continuous flow of an appropriate inert gas. Suitably equipped plastic bags [1, 2, 3, $4,5],{ }^{1}$ a section of pipe [6], the open bell jar [7], a reaction vessel [8] and a refrigerator shell [9] are of this type.

A second type is the dry-box with a constantly maintained atmosphere $[10,11,12,13,14]$ which may be regenerated and recirculated. These dry boxes are most elaborate and include electrical outlets and even gas cocks. They are not easily purged when some organic vapors are introduced. A device sometimes used to eliminate the long flushing time required is to expel the contaminated vapor in the chamber by an inflating balloon [11].

A third type can be evacuated so that repurification of the inert gas or long equilibration periods $[15,16]$ can be avoided.

The chamber described here is less expensive to build than many of those described in the literature cited or commercially available and has a greater versatility for small operations in the laboratory. It is of the evacuable type mentioned above. For the occasional transfer and bottling of various samples this type of chamber offers the least expensive method in which the atmosphere can be purged completely when vapors from one sample would contaminate the next material to be transferred.

Another advantage of the chamber described here is the ease with which the whole chamber or any portions of it can be disassembled and cleaned. The bell jar itself can be further protected against surface deposits by lining it with a removable plastic film [17].

\section{Chamber}

The chamber is illustrated in figure 1 . It consists of two main parts, the commercially available plastic bell jar, A, which measures 16 in. inside diameter and 14 in. inside height, and the base plate, B, which is a $20 \mathrm{in}$. square brass plate $1 / 2 \mathrm{in}$. thick.

\footnotetext{
1 Figures in brackets indicate the literature references at the end of this paper.
}

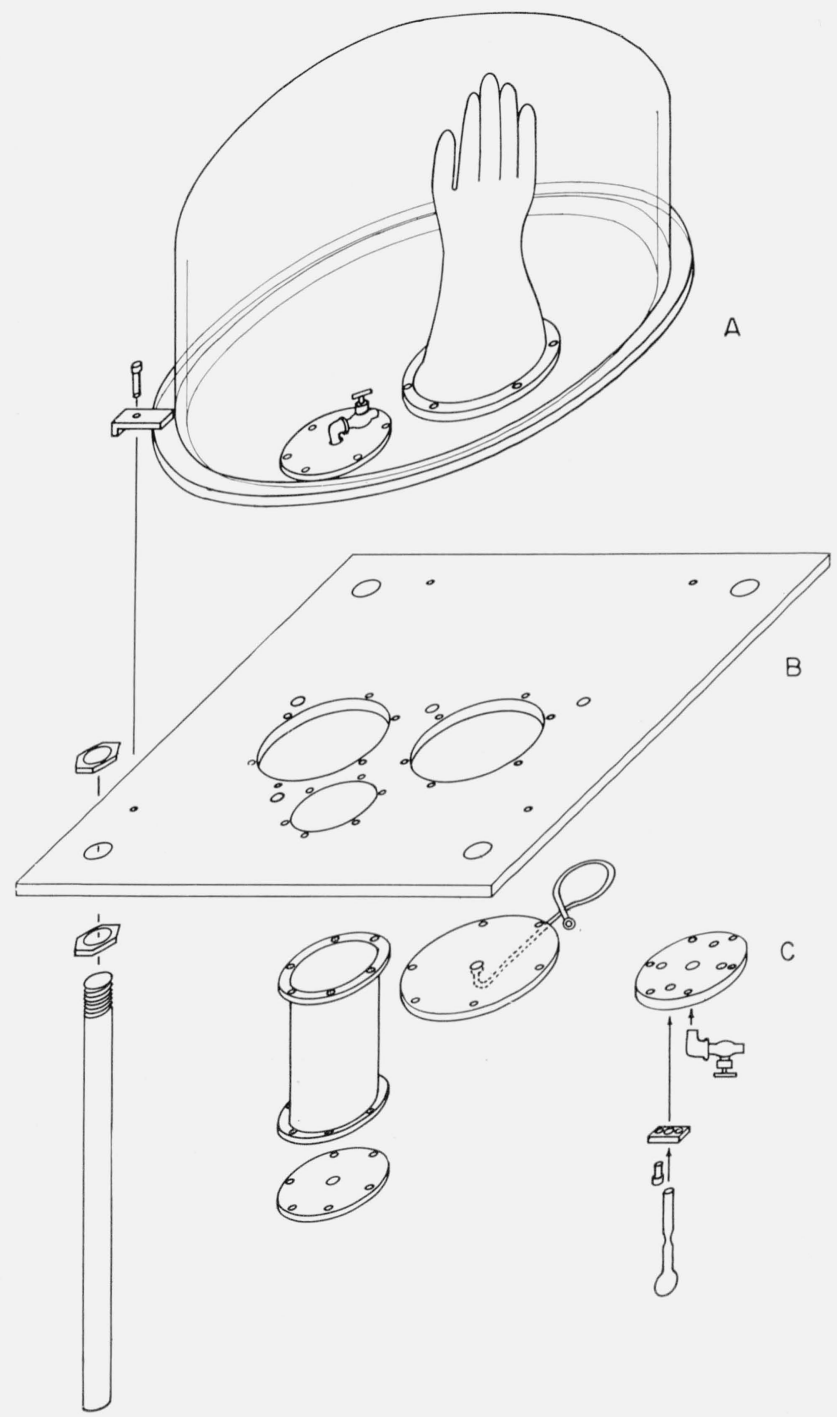

Figure 1. Assembly of the inert atmosphere chamber. Parts which are duplicated are here shown only once.

A. Plastic bell jar.

B. Base plate.

C. Sampling attachment. 
The base plate has several openings: two 5-in. diameter holes for the gloves, one 3-in. hole for an antechamber, and four holes threaded for 1/4-in. pipe, each closed by a needle valve for control of evacuation and admission of the inert atmosphere. A design using the base plate in a vertical position with a shelf on it for a working area is more convenient. However, the sampling technique described later can not be used.

The base plate has four legs (18 in. long) attached at its corners, which hold it up sufficiently high above the table top that the operator's arms can be freely moved about under the chamber while his hands are inside the chamber. Also sufficient room is available for the introduction from below of equipment into the antechamber. All the flat metal-to-metal seals are gasketed by cutouts from a 1116 in. neoprene sheet.

On both the top and bottom faces of the base plate, sets of six equally spaced, blind-tapped $(1 / 4-20)$ holes are provided, surrounding each of the glove openings and the ante-chamber opening. These tapped holes are for the $1 / 4-20 \times 1 / 2$ Hex Socket Head Cap Screws used to fasten the glove retaining rings and the inside antechamber plate on the top of the base plate. The tapped holes on the underside are for fastening the glove port cover plates and the antechamber by the same means.

Neoprene gloves $[18,19]$ are clamped over the glove holes by means of $1 / 4 \mathrm{in}$. thick brass rings of 6 in. outside, and $5 \mathrm{in}$. inside, diameter.

\section{Atmosphere}

For many uses oil-pumped helium, or argon, direct from the tanks is sufficiently inert. In our use for transferring samples of titanium salts, the gas needed to be purified further. Therefore, a tower filled with a mixture of glass beads and titanium trichloride in the lower half and a mixture of glass beads and potassium hydroxide pellets in the upper half was inserted in the gas line, the gas passing from bottom to top. This was followed by a trap packed loosely with glass wool which was immersed in liquid nitrogen (for final drying of helium or hydrogen, only).

For short periods the inert gas in the chamber can be maintained by a filled balloon [20] attached to the exit valve.

\section{Operation of the Chamber}

The gloves are folded on the top of the base plate and the antechamber plate is placed over the antechamber opening. Any apparatus which is to be needed and which can withstand evacuating is placed on the base plate and the bell jar is placed in position. The lids for the glove openings are secured in position under the base plate and are attached to the vacuum line. The antechamber with its outside lid is made fast to the bottom of the base plate. The whole apparatus and antechamber is evacuated, flushed once with dry helium, reevacuated and a flow of dry helium is then put through the chamber and allowed to escape through the antechamber to the air.
Small pieces of apparatus which cannot stand evacuation are introduced to the chamber through the antechamber, allowing the apparatus to remain in the antechamber sufficiently long to flush out all air. When using the antechamber in this way there is a distinct advantage in using a gas lighter than air so that the density difference is favorable for keeping air from entering the antechamber.

In some instances when hydrogen or helium is used and where the sweeping out of the residual air is not critical the gas can be admitted to the top of the bell jar by placing a bent tube on the gas inlet opening. Slow displacement of the air from the top of the chamber downward is thus accomplished.

\section{Sampling Attachment and Technique}

A disk $4 \frac{1}{8}$ in. in diameter was made from $1 / 2$ in. thick brass plate with six $1 / 4$ in. holes matching the set used to attach the antechamber. Four 10-mm holes and four small plates for clamping were made as indicated in the figure at $\mathrm{C}$. The clamping gasket was made by carefully cutting small rectangles of neoprene sheet to match these rectangular clamping plates and cutting a hole in each slightly under $10-\mathrm{mm}$ in diameter by means of a cork borer.

A stock of $10-\mathrm{mm}$ tubing which would just pass through the $10-\mathrm{mm}$ holes was obtained by selection from ordinary stock tubing. Pieces of this tubing about 8 in. in length were cleaned and a bulb with a breakable tip blown on one end. When positioned in the clamp, clamping gasket, and attachment plate, the seal of the tube to plate was made vacuum tight by tightening the clamp.

With the four hole plate as shown, four samples could be sealed off at a time. This can be done as follows: Four tubes marked at both ends are weighed and clamped in the plate with the open ends uppermost and projecting not more than $3 / 8$ in. above the plate. The plate with its gasket is next attached to the base plate in place of the antechamber and the valve connected to the vacuum line. The inside antechamber plate with its gasket (and with its valve closed) is placed over the antechamber hole which now has the sample tubes projecting into it from below. The valve in the sample tube plate is opened and the sample tubes evacuated, after which the inert atmosphere is introduced by closing the valve to the vacuum and opening the inside antechamber plate valve. The inside plate is released and lifted away from the antechamber opening. The samples are then introduced into the tubes after which the pressure in the chamber is reduced and the sample tubes sealed off. The sample weight is obtained as the difference between the sum of the weights of the two parts of the sealed off tube and the original weight of the tube, all corrected for buoyancy.

A controlled atmosphere chamber constructed as described above has been used for about 6 years in these laboratories and has proved to be quite satisfactory in the handling of materials which are susceptible to contamination by moisture or oxygen 
Even such sensitive material as finely divided titanium trichloride has been handled without contamination. The ease of cleaning spilled materials and the rapidity with which the apparatus can be reassembled, as mentioned above, have enhanced the value in our day to day use.

\section{References}

[1] Webb, L. A., and Softky, S. D., Rev. Sci. Instr. 24, $472-3$ (1953).

[2] Clark, T. J., Conn, P. K., and Hein, R. E., ChemistAnalyst 44, 5.5-6 (1955).

[3] Franklin, A. J., and Voltz, S. E., Anal. Chem. 28, 865 (1955).

[4] Occone, L. R., and Simkin, J., J. Chem. Educ. 39, 463 (1962).

[5] Shore, S. G., J. Chem. Educ. 39, 465 (1962).

[6] Cassatt, W. A., Jr., and Meinke, W. W., Nucleonics 13, No. 5, 63-4 (1955).

[7] Fiebig, E. C., Spencer, E. L., and McCoy, R. N., Anal. Chem. 29, 861 (1957).

[8] Naff, M. B., Chemist-Analyst 50, 54 (1961).

[9] Weyland, H. H., and Schwartz, D., J. Chem. Educ. 37, $536(1960)$
[10] Tyree, S. Y., Jr., J. Chem. Educ. 31, 603-5 (1954).

[11] Sherfey, J. M., Ind. Eng. Chem. 46, 435-40 (1954)

[12] Kelman, L. R., Wilkinson, W. D., Shuck, A. B., and Goertz, R. C., Nucleonies 14, No. 3, 61-5, No. 4, 65-71, and No. 5, 77-82 (1956).

[13] Gibb, T. R. P., Jr., Anal. Chem. 29, 584-7 (1957).

[14] Johnson, R. E., J. Chem. Educ. 34, 80-2 (1957).

[15] Ketchen, E. F., Trumbore, F. A., Wallace, W. E., and Craig, R. S., Rev. Sci. Instr. 20, 524 (1949)

[16] Thomas, G. R., and Lichtin, N. N., Rev. Sci. Instr. 23, 738-40 (1952).

[17] Nelson, P. R., Jr., and Slawek, J. E., Jr., Rev. Sci. Instr. 29, 253 (1958).

[18] Rowan, J. H., Anal. Chem. 28, 402-3 (1956).

[19] Norton, F. J., J. Appl. Phys. 28, 34-9 (1957).

[20] Vanderwerf, C. A., Chemist-Analyst 43, 107 (1954).

(Paper 67A3-215) 


\section{Publications of the National Bureau of Standards*}

\section{Selected Abstracts}

The construction of calorimeters for the measurement of absorbed dose, B. Petree and G. Ward, NBS Tech. Note 163 (November 1962), 25 cents.

Direct measurements of energy locally absorbed in irradiated materials can be made with adiabatic calorimeters of suitable design. Design criteria imposed by requirements of accuracy include limitations on size and complexity. Small calorimeters of simple design with precision better than one percent at dose rates above one rad per second have been developed. Details of fabrication, auxiliary equipment and performance are described.

An atlas of whistlers and VLF emissions, A survey of VLF spectra from Boulder, Colorado, D. L. Jones, R. M. Gallet, J. M. Watts, D. N. Frazer, NBS Tech. Note 166 (PB181454) (January 1963), \$2.25.

Naturally occurring VLF noises are classified and spectrograms illustrating each class are presented.

The report is divided into six sections. The first section consists of the systematic classification of VLF noises. Samples of whistlers are VLF emissions are shown in the second and third sections, respectively. The next section gives examples of interactions between these two classes. Section 5 consists of some exceptionally active periods during magnetic disturbances. The last section is a synoptic survey for the 4 months, March through June, 1957. A spectrogram is given for every observation period containing any VLF activity.

Most of the data was recorded at the Sunset Field Station of the National Bureau of Standards, Boulder, Colo., during $1956-57$.

The above National Bureau of Standards Technical Note is available by purchase from the Office of Technical Services, U.S. Department of Commerce, Washington 25, D.C. (please order by PB number).

Growth rates of potassium crystal from the vapor phase, R. L. Parker, J. Chem. Phys. 37, N0. 8, 1600-1605 (Oct. 1962). Measurements of the growth rate of potassium (110) faces, for low vapor supersaturations $\sigma$ between 3.1 and 0.11 (the lowest value studied) have given unit condensation coefficients for all supersaturations. This results is in agreement with the theory of Burton, Cabrera, and Frank, and gives the values $\beta \mathrm{Co}=1, \sigma_{1} \leq 0.046$ for potassium. No evidence of 2-dimensional surface nucleation was found. Careful attention to the reduction of impurities, through the use of ultrahigh vacuum techniques, was shown to be necessary in studying this system. Results of earlier work by Hock and Neumann on potassium can be well described by an application of the Cabrera-Vermilyea theory of impurity effects, with an effective partial pressure of active gases of $1 \times 10^{-11}$ $\mathrm{mm} \mathrm{Hg}$. In the present experiments this value is less than $3 \times 10^{-13} \mathrm{~mm} \mathrm{Hg}$. The unit condensation coefficients are shown to be in disagreement with a theoretical prediction of Hirth and Pound.

The NBS photoelectric pyrometer of 1961, R. D. Tee, Book Temperature, Its Measurement and Contro! in Science and Industry 3, Pt. 1, 507-151 (Reinhold Publ. Corp., New, N.Y., 1962).

A photoelectric pyrometer is described which differs from a visual optical pyrometer mainly in that radiance matches are detected photoelectrically instead of visually. Its precision for a radiance temperature measurement at $1063^{\circ} \mathrm{C}$ is 0.02 deg $\mathrm{C}$ or less (sample standard deviation), accomplished with a spectral passband, centered on $6530 \mathrm{~A}$, that has a width at half-height of $110 \mathrm{~A}$. The instrument is undergoing test for accuracy and stability preparatory to calibration in accordance with the International Practical Temperature Scale above $1063{ }^{\circ} \mathrm{C}$. The investigation to date has uncovered possible inaccuracies of 0.1 to $0.2 \mathrm{deg} \mathrm{C}$ related to the size of the source used. The origin is still not known. However, the radiance match is correctable, if different sized sources are to be used in the primary calibration and subsequent temperature measurements without resorting to direct measurements of the area of the sources. Stability experiments with four aged pyrometer lamps with a constant current comparable to a radiance temperature of $1063{ }^{\circ} \mathrm{C}$ showed the most stable lamp to change by $0.3 \operatorname{deg} \mathrm{C}$ in 700 hours and the least stable to change by $0.5 \mathrm{deg} \mathrm{C}$ in 150 hours. The magnitude of these instabilities is unexpected and is being investigated further.

Heat transfer in intensively outgassed powders, R. C. Little, F. G. Carpenter, and V. R. Deitz, J. Chem. Phys. 37, No. 8, 1896-1898 (Oct. 15, 1962).

Cooling curves were determined for powders intensively outgassed at $600^{\circ}$ and then immersed in liquid oxygen. The behavior of these indicated a much slower thermal transport than has been reported. The cooling rate increased sharply when an adsorbing gas ( $\mathrm{A}, \mathrm{Kr}, \mathrm{N}_{2}$ ) was introduced to the evacuated powder. The greatest change in cooling rate was observed when the added gas resulted in steady-state fractional coverage in the range between 0.01 and 0.06 . The great enchancement of heat transfer by small amounts of added gas indicated a significant contribution to heat transfer by surface transport in a mobile adsorbed gas film

Rates of thermal degradation of organic polymers, S. L. Madorsky, SPE J.18, No. 12, 1482-1490 (Dec. 1962).

The use of plastics in modern industry, particularly in space technology and at temperatures far above the ordinary, makes it imperative to have an understanding of the chemistry and kinetics of their thermal degradation. The chemical phase of this problem has been treated in an earlier article in the SPE Journal. In this article, the kinetics phase is discussed primarily from the angle of rates, activation energies, and order of the reactions involved.

Vacuum ultraviolet photochemistry. V. Photolysis of isobutane, H. Okabe and D. A. Becker, J. Am. Chem. Soc. 84, No. 21, 4004-4007 (1962).

The photolysis of isobutane was carried out at room temperature at $1470 \AA$ and $1236 \AA$. Certain specifically labeled deuterium compounds were used to gain information on the mechanisms of product formation. From isotopic analysis of products, hydrogen, methane and ethane, in the photolysis of an equimolar mixture of isobutane + isobutane- $\mathrm{d}_{10}$ the following conclusions were drawn.

(1) Hydrogen is formed both from atomic and molecular processes. The atomic process becomes more important at the shorter wavelength (1236 $\AA$ ). From scavenger experiments, it was found that approximately half the hydrogen is formed by the atomic process at $1470 \AA$. (2) Methane is predominantly formed by a molecular process at $1470 \AA$ and $1236 \mathrm{~A}$. (3) Ethane is formed primarily by the combination of methyl radicals. From the photolysis of isobutane-a-d, it was concluded that (a) there is no apparent preference of the position (primary or tertiary) for the expulsion of atomic hydrogen at $1470 \mathrm{~A}$. However there is some discrimination with regard to position for the hydrogen produced by molecular climination. (b) The primary and tertiary hydrogen participate almost equally in the intramolecular production of methane. Reactions responsible for the formation of other products, ethylene, propane, propylene, isobutene, neopentane, and isopentane, are discussed.

Traces of products of angular momentum matrices. II. Sperical basis, E. Ambler, J. C. Eisenstein, and J. F. Schooley, J. Math. Phys. 3, No. 4, 760-771 (July-Aug. 1962). 
Closed formulas are given for $\operatorname{Tr} J_{\alpha}{ }^{P} J_{\beta}{ }^{a} J_{\gamma} r 1 \ldots$ where $\alpha$ $\beta, \gamma \ldots$ are equal to $+1,0$ or -1 , and $p, q, r$ are non-negative integers for which $p+q+r+\ldots \leq 9$. The procedures used in evaulating the traces are described. In order to facilitate numerical evaluation from existing tables, simple relationships are given between traces in the spherical basis and traces in the Cartesian basis. The use of these tables for evaluating expectation values of certain operators is discussed in relation to other methods based on the coupling and recoupling theory of angular momentum.

A study of stability of high temperature platinum resistance thermometers, J. P. Evans and G. W. Burns, Book, Temperaature, Its Measurement and Control in Science and Industry 3, Pt. 1, 313-318 (Reinhold Publ. Corp., New York, N.Y., 1962)

The National Bureau of Standards is studying the performance of platinum resistance thermometers in the range $630.5^{\circ}$ to $1063{ }^{\circ} \mathrm{C}$. A number of thermometers with temperature sensing resistors of several designs, various protecting tube materials, and two types of platinum wire have been constructed. Thermometer stability was tested by heating the thermometers for long times at high temperatures and periodically determining the thermometer resistance at $100^{\circ}$ and $0{ }^{\circ} \mathrm{C}$. The constancy of the ratio of these resistances, $\mathrm{R}_{100} / \mathrm{R}_{0}$, is taken as an indicator of thermometer stability. It is shown that stable thermometers can be made. The stability of the thermometers is found to be affected by the rate of cooling from high temperatures. This cooling rate effect is explained by the quenching-in of point defects in platinum.

The present state of atomic spectra, C. M. Moore-Sitterly, Japan Anal. 11, No. 11, 1199-1202 (1962).

Summary of lecture given on September 5, 1962, at the University of Tokyo to the Spectroscopical Society of Japan

Correlation factors for impurity diffusion - fcc lattice, J. R. Manning, Phys. Rev. 128, No. 5, 2169-2174 (Dec. 1962)

The correlation factor $f$ for an isolated impurity atom diffusing by a vacancy mechanism in a face-centered cubic lattice is calculated in terms of five vacancy jump frequencies near the impurity, $w_{0}, w_{1}, w_{2}, k_{1}$, and $k_{2}$, as defined by Lidiard (Phil. Mag. 46, 1218 (1955)). In general, the correlation factor can be expressed as $f=\left(2 w_{1}+7 F k_{1}\right) /\left(2 w_{2}+2 w_{1}+7 F k_{1}\right)$, where $F$ is a function of $k_{2} / w_{0}$. In the limit where $k_{2} / w_{0} \rightarrow 0$, $F$ goes to unity. In the limit where $k_{2} / w_{0} \rightarrow \infty, F$ goes to $2 / 7$. When the five frequencies above are the only vacancy jump frequencies in the crystal, an expression for $F$ as a function of $k_{2} / w_{0}$ can be found from a Bardeen-Herring calculation. It is found that

$$
F=1-\frac{S}{7}\left\{\frac{11.56+50.10 \Delta+40.00 \Delta^{2}}{0.521+4.69 \Delta+12.06 \Delta^{2}+8.00 \Delta^{3}}\right\},
$$

where $S=k_{2} / 12 w_{0}$ and $\Delta=\left(k_{2}-w_{0}\right) / 12 w_{0}$. This method can be extended to other lattices. Applications to data in the literature are discussed.

Experimental proof of the absence of equilibrium in a helium arc, A. T. Hattenburg and H. J. Kostkowski, Book, Temperature, Its Measurement and Control in Science and Industry $\mathbf{3}$, Pt. 1, 587-592 (Reinhold Publ. Corp., New York, N.Y., 1962). An atmospheric pressure helium are containing $6 \times 10^{15}$ electrons per cubic centimeter on its axis was investigated by spectroscopic methods to determine the extent of local thermodynamic equilibrium. Relative intensity measurements of a number of singlet and triplet neutral helium lines did not indicate the absence of equilibrium. However, the radial increase of the temperature determined from the absolute intensity measurement of the 5016A helium line, combined with the radial decrease of temperature obtained from electron density determinations and the Saha equation, did establish the lack of local thermodynamic equilibrium in this source.

Dissociation constant of t-butylammonium ion and related thermodynamic quantities from 5 to $35^{\circ}$, H. B. Hetzer, R. A. Robinson, and R. G. Bates, J. Phys. Chem. 66, 2696 (1962)
The acidic dissociation constant of $t$-butylammonium ion has been determined from $5^{\circ}$ to $35^{\circ}$ by e.m.f. measurements of hydrogen-silver bromide cells without liquid junction. At $25^{\circ},-\log K_{b h}=10.685$, and the temperature coefficient of the dissociation constant gives the values $\Delta H^{\circ}=60,070 \mathrm{~J}$ mole $^{-1}$ and $\Delta S^{\circ}=-3.1 j$ mole $^{-1} \mathrm{deg} .^{-1}$. These thermodynamic constants are compared with the corresponding values for the acidic dissociation of the protonated forms of the aminoalcohols related structurally to $t$-butylamine.

Measurement of electron density and temperature in dense plasmas by application of line broadening theory, J. B. Schumaker, Jr., and W. L. Wiese, Book, Temperature, Its Measurement and Control in Science and Industry 3, Pt. 1, 575-579 (Reinhold Publ. Corp., New York, N.Y., 1962).

The electron density and temperature in arc plasmas have been determined by the deliberate introduction of a trace of hydrogen as a thermometer. The electron density is obtained by spectrophotometric measurement of the line profile of one of the Balmer lines and comparison with the theoretical profiles recently calculated by Griem, Kolb, and Shen. The temperature is then calculated from the electron density using the usual equilibrium equations of statistical mechanics for reacting gases.

Germanium vacuum ultraviolet Ritz standards, V. Kaufman and K. L. Andrew, J. Opt. Soc. Am. 52, No. 11, 1223-123y (Nov. 1962).

The number of germanium Ritz standards below $2000 \AA$ has now been increased to approximately 100 lines with estimated uncertainties not exceeding $0.0008 \AA, 68$ of which have estimated uncertainties of $0.0003 \AA$. This extension is the end product of a systematic Fabry-Perot interferometric investigation which has extended the former interferometric region of $2019 \AA-4685 \AA$ to $12069 \AA$. Ninety-five interferometrically determined levels of GeI are given, 72 of which have been improved by this effort.

Twenty-three lines of GeII were also measured interferometrically, leading to a few improved energy levels of this spectrum and to estimated splittings of the $n g^{2} \mathrm{G}(n-5,6,7)$ terms. An improved Series Limit of Ge II calculated from the $4 f^{2} \mathrm{~F}-n g^{2} \mathrm{G}$ series is $128535.8 \mathrm{~cm}^{-1}$.

Vapor phase growth kinetics of $\mathrm{Hg}$ and $\mathrm{K}$ whiskers by field emission, R. L. Parker and S. C. Hardy, J. Chem. Phys. 37, No. 8, 1606-1609 (Oct. 1962).

Using the method originated by Gomer, we have studied the growth kinetics of mercury and of potassium whiskers, as they grow from the vapor phase in an electron field emission tube. To the best of our knowledge, the work on potassium represents the first use of an alkali metal as a field emitter. Most of our results on mercury whiskers agree with those obtained earlier by Gomer, including the positive exponential length growth (110), orientation, attainment of terminal lengths, and the surface diffusion coefficients; there are some differences, however.

The results for potassium whiskers show some features similar to those found for mercury, and some new features. The former include positive exponential growth, and the attainment of therminal lengths. New features include the absence, usually, of symmetric emission patterns; a very low activation energy for surface self-diffusion; the fact that the whiskers cannot be pulled off but instead appear to shorten gradually if the field is raised; and finally, an interesting sensitivity of the growth processes to illumination of the whiskers with visible light.

The determination of absolute temperatures from sound velocity measurements, G. Cataland, M. H. Edlow, and H. H. Plumb, Book, Temperature, Its Measurement and Control in Science and Industry 3, Pt. 1, 129-132 (Reinhold Publ. Corp., New York, N.Y., 1962).

Absolute temperatures were derived from determinations of the velocity of sound in a gas and the acoustical interferometer was used for the velocity measurements. For an ideal gas, the velocity of sound is directly proportional to the square root of the absolute temperature; in the case of a real gas, corrections must he made which involve virial coefficients of the gas in a pressure expansion. Since these corrections are 
a function of pressure, it is desirable that velocity measurements for absolute temperature determinations be conducted at the lowest practical pressures (the real gas approaches the state of an ideal gas).

An acoustical interferometer has been constructed at the National Bureau of Standards and has been used, with helium gas as a thermometric material, to determine absolute temperatures at $4.2^{\circ} \mathrm{K}$. When temperatures thus derived are compared with absolute temperatures associated with liquid helium vapor pressures, the difference between the two temperatures is 10 millidegrees. While this result is of a preliminary nature, it does justify continued investigations for determining absolute temperatures by sonic methods.

The role of temperature in our measuring system, A. G. McNish, Book, Temperature, Its Measurement and Control in Science and Industry 3, Pt. 1, 129-132 (Reinhold Publ. Corp., New York, N.Y., 1962).

Temperature is taken, together with length, mass, and time, as one of the completely independent quantities which form the basis of our measuring system. This is noteworthy in that temperature is an intensive quantity while the other three are extensive quantities. The unit of temperature, like the units of length, mass, and time, is independent of all units of the system, being like them, embodied in its proper standard It is possible to construct a system in which temperature is not regarded as an independent quantity but one expressible in terms of length, mass, and time. However, in such a system the unit of temperature could not be realized with anything like the accuracy required for good measurements. This is because the relationship between temperature and length, mass, and time has not yet been measured with an accuracy approaching that with which each of these quantities itself can be measured. Specifically, the gas constant has never been very accurately determined.

The present practice of regarding temperature as an independent quantity affords a procedure for the most accurate measurement of temperature.

Microwave Doppler measurements of the ionization front in cylindrical shock waves from exploding wires, D. L. Jones and R. M. Gallet. Exploding Wires 2, 127-144 (1962).

Strong cylindrical shock waves from exploding wires have been measured by microwave Doppler techniques. The results obtained simultaneously on two or three independent frequencies are in very good agreement and show that the ionization front is well defined. The Taylor-Lin similarity blast wave theory for the shock wave propagation is well verified over distances up to 6 or 7 centimeters under the present conditions. Systematic results for the determination of shock wave energy and the efficiency for shock production in air over a range of pressures, wire diameters, and stored electrical energy are presented. Relative to optical methods used in the same problem the present technique is more sensitive and perhaps more precise.

It is remarkable that very good reflections are still consistently obtained when the shock Mach falls below 3 in air. From the calculated temperature and ionization in the shock front, the expected electron density should then be negligible. This effect is probably a result of the preexcitation of the gas ahead of the shock front, caused by ultraviolet radiation from the wire explosion or from the advancing shock front itself. There is also a relatively weak precursor ionization, for which recent microwave absorbtion measurements have indicated electron densities of the order of $10^{12} \mathrm{~cm}^{-3}$ several centimeters ahead of the front. The good reflection at low Mach numbers permits one to show that the similarity theory is still valid until Mach number 4 or below, and permits one also to record the departure form this relation at larger radii.

Temperature dependence of elastic constants of vitreous silica, S. Spinner, J. Am. Ceram. Soc. 45, No. 8, 394 (Aug. 1962). The relation between the elastic moduli and temperature from room temperature to about $1300{ }^{\circ} \mathrm{C}$ was determined for a group of vitreous silica specimens by a dynamic resonance method. All the curves were approximately parabolic in shape, reaching a maximum around 1050 to $1200{ }^{\circ} \mathrm{C}$. At the maximum value, Young's modulus was more than 11 percent higher and the shear modulus about 9 percent higher than their room temperature values. Poisson's ratio was then computed to rise from about one-sixth at room temperature to about one-fifth at the temperature of maximum elastic modulus. Small but significant differences were observed in the temperature-modulus curves for specimens from different manufacturers.

Comments on the limits to the refractive index at ground level as a radio-meteorological parameter, B. R. Bean and G. D. Thayer, Proc. IRE 48, No. 8, 1498-1501 (A ug. 1960). A summary discussion on the use of net rate processes and the equivalent 2-level atom in non-LTE computations.

Rate of spherulitic crystallization with chain folds in polychlorotrifluoroethylene, J. D. Hoffman and J. J. Weeks, J. Chem. Phys. 37, No. 8, 1723-1741 (Oct. 1962).

Parameters related to the recently proposed "kinetic" viewpoint of homogeneous nucleation and growth of lamellar polymer crystals with chain folds are obtained. The nucleation constant $K_{\mathrm{g}}$ is analyzed to obtain $\sigma \sigma_{e}=184 \mathrm{erg}^{2} / \mathrm{cm}^{4}$ $\left(\sigma=\right.$ lateral surface free energy, $\sigma_{e}=$ end (chain folded) surface free energy). A similar value of $\sigma \sigma_{e}$ is obtained form bulk crystallization studies. The homogeneous nucleation process was identified at $\Delta T_{h}=70{ }^{\circ} \mathrm{C}$, and a value of $\sigma^{2} \sigma_{e}=950$ $\mathrm{erg}^{3} / \mathrm{cm}^{6}$ calculated from $K_{a}$ in $I=(N k T / h) \exp \left(-\Delta F^{*}\right)$ $\exp \left[-K_{n} / T^{3}(\Delta T)^{2}\right]$. Combination of $\sigma^{2} \sigma_{e}$ and $\sigma \sigma_{e}$ gives $\sigma=5.2 \mathrm{erg} / \mathrm{cm}^{2}$ and $\sigma_{e}=36 \mathrm{erg} / \mathrm{cm}^{2}$, the latter corresponding to a work on chain folding, $q$, of $3.9 \mathrm{kcal} / \mathrm{mole}$ of folds. A value of $\sigma=5.1 \mathrm{erg} / \mathrm{cm}^{2}$ is obtained independently using an empirical method. Further, an independent estimate of $\sigma_{e}=35+7 \mathrm{erg} / \mathrm{cm}^{2}$ is obtained for PCTFE from lamellar thickness studies, after accounting for the increase of thickness that occurs sebsequent to initial growth using melting point data. The overall role of $q$ in homogeneous nucleation and growth in linear polymers is discussed using PCTFE and polyethylene as examples. The "kinetic" chain fold theory gives a consistent picture of surface free energies, rates of homogeneous nucleation and growth, melting behavior, variation of initial step height with temperature, and formation of chain-folded lamellae.

An experimental investigation of overall heat transfer coefficients for condensing and boiling hydrogen films, K. D. Timmerhaus, D. E. Drayer, and J. W. Dean, Intern. Develop. Heat Transfer (ASME) \&, 270-278 (1961).

Overall heat rransfer coefficients for condensing and boiling hydrogen films have been determined for temperature gradients ranging from $0.38^{\circ}$ to $6.0^{\circ} \mathrm{F}$ for a single smooth vertical brass tube. Temperature difference between the condensing and boiling films was regulated and observed by changes in vapor pressure. Overall heat transfer coefficients under these experimental conditions are plotted not only as a function of the temperature difference but also of the heat flux and are compared as far as possible with known values in the literature. Further investigations are being made to evaluate the individual heat transfer coefficients and the effect of surface conditions on the overall heat transfer coefficient.

The photolysis and radiolysis of $\mathrm{CH}_{3} \mathrm{~N}_{2} \mathrm{CH}_{3}$ and $\mathrm{CH}_{3} \mathrm{~N}_{2} \mathrm{CH}_{3}$ $\mathrm{CD}_{3} \mathrm{H}_{2} \mathrm{CD}_{3}$ mixtures, R. E. Rebbert and P. Ausloos, J. Phys. Chem. 66, No. 11, 2253-2258 (Nov. 1962).

Azomethane has been photolyzed in the solid, liquid, and gaseous phases. In the gas phase photolysis, evidence has been obtained for the formation of ethane by a molecular elimination from azomethane. The quantum yield of the formation of nitrogen in the liquid phase is lower than unity and decreases with decrease in temperature, benzene quenches and 2,3-dimethylbutane enhances the decomposition yield. The effect of collisional deactivation, molecular elimination and free radical recombination in the cage on the total yield of ethane is discussed.

Radiolysis experiments on mixtures of $\mathrm{CH}_{3} \mathrm{~N}_{2} \mathrm{CH}_{3}-\mathrm{CD}_{3} \mathrm{~N}_{2} \mathrm{CD}_{3}$ were performed in the liquid and solid phases. The results indicate that ethane is mainly formed by cage and intercage recombination in the $\gamma$-ray spur. A decrease in temperature and addition of solvents has a reducing effect on the relative yield of $\mathrm{CH}_{3} \mathrm{CD}_{3}$. Evidence for energy transfer from benzene to azomethane was obtained.

A molecular-orbital study of the geometry of $\mathrm{HO}_{2}$, M. E. 
Boyd, J. Chem. Phys. 37, No. 6, 1317-1325 (Sept. 1962). Determination of the energy of $\mathrm{HO}_{2}$ as a function of the $\mathrm{HO}_{1} \mathrm{O}_{2}$ angle for fixed values of $\mathrm{R}\left(\mathrm{H}-\mathrm{O}_{1}\right)$ and $\mathrm{R}\left(\mathrm{H}-\mathrm{O}_{2}\right)$ have been carried out using $\mathrm{LCAO}-\mathrm{MO}-\mathrm{SCF}$ calculations on closed shell ions. All one-electron and one and two center two-electron integrals used were evaluated accurately while three center integrals were approximated. An isosceles triangle configuration is favored by these calculations and gives a value of the ionization potential of $9.5 \mathrm{e} . \mathrm{v}$. and dissociation energy of 4.4 e.v., consonant with experimental results.

Approximation by means of ionic calculations used here is shown to be valid for the purposes of this discussion.

Isotope effect in the recrystallization of D-mannose-1-t phenylhydrazone, F. Weygand, H. Simon, K. D. Keil, H. S. Isbell, and L. T. Sniegoski, Anal. Chem. 34, 1753-1755 (Dec. 1962).

An isotope effect previously reported in the recrystallization of D-mannose-1-t phenylhydrazone has been reinvestigated and confirmed. The ratio of the rate of crystallization of the isotopic to that of the nonisotopic form $\left(\mathrm{k}^{*} / \mathrm{k}\right)$ was found to be 0.88 .

Reaction of methyl- $d_{3}$ radicals with isobutane, isobutane-2d and propane, W. M. Jackson, J. R. MeNesby, and B. deB. Darwent, J. Chem. Phys. 37, No. 8, 1610-1615 (Oct. 1962). The relative rates of abstraction by $\mathrm{CD}_{3}$ radicals of primary, secondary, and tertiary $H$ atoms have been measured. Using a standard rate constant for abstraction of $\mathrm{D}$ from acetone- $d_{6}$, the following rate constants are obtained.

(2) $\mathrm{CD}_{3}+\mathrm{CD}_{3} \mathrm{COCD}$

3) $\mathrm{CD}_{3}+\left(\mathrm{CH}_{3}\right)_{3} \mathrm{CD}$

4) $\mathrm{CD}_{3}+\left(\mathrm{CH}_{3}\right)_{3} \mathrm{CD}$

$\mathrm{CD}_{4}+\mathrm{CD}_{2} \mathrm{COCD}_{3}$

$\begin{array}{ll}\mathrm{CD}_{4}+\left(\mathrm{CH}_{3}\right)_{3} \mathrm{C} & 0.88 \times 10^{10} \mathrm{~T}^{1} / 2 \exp (-9200 / \mathrm{RT})\end{array}$

$\mathrm{k}\left(\mathrm{mole}^{-1} \mathrm{cc} \mathrm{sec}^{-1}\right)$

Isotope effects obtained are, for secondary $\mathrm{H}$ and D in propane:

$$
\mathrm{k}_{\mathrm{H}} / \mathrm{k}_{\mathrm{D}}=1.04 \exp (1400 / \mathrm{RT})
$$

and for tertiary $\mathrm{H}$ and $\mathrm{D}$ in isobutane:

$$
\mathrm{k}_{\mathrm{H}} / \mathrm{k}_{\mathrm{D}}=0.80 \exp (1600 / \mathrm{RT})
$$

These isotope effects are within experimental error of that given by the general expression for the deuterium isotope effect previously proposed

$$
\mathrm{k}_{\mathrm{H}} / \mathrm{k}_{\mathrm{D}}=\exp (1500 / \mathrm{RT})
$$

and are in excellent correspondence with the theorectical treatment of Johnston and Rapp.

Theory and methods of optical pyrometry, H. J. Kostkowski and R. D. Lee, Book, Temperature, Its Measurement and Control in Science and Industry 3, Pt. 1, 449-481 (Reinhold Publ. Corp., New York, N.Y., 1962).

A detailed review of the theoretical methods of optical pyrometry and the application of these methods at the National Bureau of Standards in realizing and dispersing the International Practical Temperature Scale above $1063{ }^{\circ} \mathrm{C}$ is presented. In the theoretical presentation, the concepts of effective and mean effective wavelengths are introduced, and various equations relating these parameters to each other and other physical quantities are derived. The important features of precision visual optical pyrometers are discussed and a number of blackbody sources and tungsten strip lamps described. Detailed experimental procedures and results of of primary and secondary calibrations of optical pyrometers at NBS are given. Finally, recommendations for achieving high precision and accuracy and the fundamental limitations in visual optical pyrometry are presented.

Measurement of effective temperatures of microwave noise sources, J. S. Wells, W. C. Daywitt, and C. K. S. Miller, IRE Intern. Conv. Record, Pt. 3, 220-238 (1962).

This report describes a system now in operation for the purpose of calibrating microwave noise sources at three selected frequencies in the range 8.2 to $12.4 \mathrm{Gc}$. Included are a discussion of the reference standard noise source, an error analysis of the standard source and the comparison system, and evidence of system performance. Results of measurements indicate that the excess noise ratio of a specific commercial argon filled noise source is $15.6 \mathrm{db}$ at $9.8 \mathrm{Gc}$

The calibration of temperature standards on the international practical temperature scale of 1948, J. P. Evans, Proc. 17th Ann. Instrument.-Automation Conf. Exhibit, Instr. Soc. Am. Preprint No. 21-1-62 (New York, N.Y., Oct. 1962).

The International Practical Temperature Scale of 1948 is maintained in this country by the National Bureau of Standards. This paper describes techniques used at NBS to calibrate temperature measuring devices on the scale and methods of transferring the scale to industrial temperature standards.

The structure of lithium dipotassium trimetaphosphate monohydrate, E. D. Eanes and H. M. Ondik, Acta Cryst. 15, Pt. 12, 1280-1285 (Dec. 1962)

$\mathrm{LiK}{ }_{2} \mathrm{P}_{3} \mathrm{O}_{9} \cdot \mathrm{H}_{2} \mathrm{O}$ is monoclinic, space group $\mathrm{P} 2 / c$, with cell dimensions: $a=8.669 \pm 0.003, b=14.497 \pm 0.004, c=7.634 \mathrm{~A}$, $\pm 0.006, \quad \beta=99^{\circ} 53^{\prime} \pm 3^{\prime}, Z=4$. The structure was determined from a three-dimensional Patterson function, and refined by electron-density syntheses and complete matrix least squares. The final $R$ value for 1,011 independent observed reflections is 0.099 .

The trimetaphosphate anion consists of three orthophosphate tetrahedra joined at corners to form a six-membered ring of alternate phosphorus and oxygen atoms in a chair configuration. The phosphate tetrahedra are nearly regular. The two potassium ions have irregular coordination figures. One is surrounded by six oxygen atoms from five different anions and the water molecule. The other is surrounded by eight oxygens, two oxygens from each of four different anions. The lighium ion is found at the center of a fairly regular tetrahedron formed by three oxygens and the water. The cation polyhedra are linked at edges and corners to produce equal cohesion in all directions, thus accounting for the lack of cleavage.

An improved resistance thermometer bridge, J. P. Evans, Book, Temperature, Its Measurement and Control in Science and Industry 3, Pt. 1, 285-289 (Reinhold Publ. Corp., New York, N.Y., 1962).

Details of an improved Mueller bridge are given. The bridge has a range 0 to $422 \mathrm{ohms}$ in 1 microhm steps. The important new features are (1) the addition of a decade with 1 microhm steps; (2) the use of mercury wetted contact switches for the $1,0.1$, and $0.01 \mathrm{ohm}$ decades as well as for the $10 \mathrm{ohm}$ decade and the $100 \mathrm{ohm}$ coils; (3) the use of totally enclosed wafer type switches for the four lower decades; (4) the inclusion of a circuit which permits the instrument to be used as a four terminal decade resistor; (5) provision for digital readout of the bridge dial settings; and (6) electrical guarding and shielding of the measuring circuit so that sensitive electronic null detectors may be used.

Resistance thermometry in the liquid helium temperature region, M. H. Edlow and H. H. Plumb, Book, Temperature, Its Measurement and Control In Science and Industry 3, Pt. 1, 407-411 (Reinhold Publ. Corp., New York, N.Y., 1962).

Carbon and impurity doped germanium resistors have been investigated for use as precision secondary thermometers in the liquid helium temperature region. Three germanium resistors supplied by Bell Telephone Laboratory $(86 \Omega, 59 \Omega$, and $21 \Omega$ ) have been thermally cycled from $300^{\circ} \mathrm{K}$ to $4.2^{\circ} \mathrm{K}$ and their resistances have been found to be reproducible to within 1 millidegree when temperatures were derived from a controlled surface vapor pressure, and within $1 / 3$ millidegree (except for one that had been repaired) when temperatures were derived from a vapor pressure thermometer whose tubing is jacketed through most of the liquid helium. Five impurity-doped germanium resistors supplied by Texas Instruments, Inc., have been thermally cycled from $300{ }^{\circ} \mathrm{K}$ to $4.2^{\circ} \mathrm{K}$ and yield reproducibilities ranging from 2 to 10 millidegrees. Preliminary calibrations of the Bell Laboratory $59 \Omega$ and $21 \Omega$ and the Texas Instruments Inc. $125 \Omega$ resistors have been made from $4.21^{\circ} \mathrm{K}$ to $2.16^{\circ} \mathrm{K}$ at every $.1^{\circ} \mathrm{K}$. The 
data were fitted to a curve of the form $\log R+k / \log$ $R=A+B_{l}^{\prime} T$ by means of the 704 computer. The standard deviations of the data from this equation for the $125 \Omega$ and $59 \Omega$ resistors are $\leqq 1$ millidegree; for the $21 \Omega$ resistor, the standard deviation is $\leqq 3.3$ millidegrees.

A National Bureau of Standards gas thermometer, L. A Guildner, Book, Temperature Its, Measurement and Control in Science and Industry 3, Pt. 1, 151-155 (Reinhold Publ. Corp. New York. N.Y., 1962).

At the National Bureau of Standards a constant-volume gas thermometer will be used to determine differences between the International Practical Temperature Scale of 1948 and the Kelvin thermodynamic scale. The gas thermometer thermometer bulb is a $500 \mathrm{cc}$ shpere of platinum-20\% rhodium alloy. It is connected to a pressure-sensitive diaphragm for separating the gas thermometer from a mercury manometer. With large menisci, the positions of the mercury crowns can be accurately detected by capacitance. The height of mercury is measured by Hoke end standards. A "tilt meter" measures variations of the manometer base from level.

Intensive effort is being made to reduce random and systematic errors. The bulb is thermostated uniformly by a copper furnace. The physical characteristics of the gas thermometer will be determined experimentally. Measurements will be made with a second thermometer bulb and with more than one gas. Determinations will be made for different masses of each gas in order to extrapolate to zero pressure.

It is planned to measure near the fixed points and at intermediate temperatures from $100{ }^{\circ} \mathrm{C}$ to $960{ }^{\circ} \mathrm{C}$. A final set of measurements will determine the ratio of the thermodynamic temperatures of the steam and triple points of water.

Quartz crystals at low temperatures, P. R. Simpson and A. H. Morgan, Proc. 13th Annual Symp. Frequency Control, $p$. 207-231 (Aug. 1959).

The results of measurments performed at NBS Boulder Laboratories on certain characteristics of high precision quartz crystal oscillator units at temperatures below the normal ambient range are described with particular emphasis on frequency stability. Included are some details on the cryogenic ovens used, their tenperature control devices and performance. The oscillators developed for driving the crystal units and the frequency measuring systems employed will also be discussed. Various disturbing influences such as recharging the cryostats with refrigerant, shock, and vibration, filament voltage variations on the oscillator tubes, and others, will be mentioned.

Precursor electrons ahead of cylindrical shock waves, D. L. Jones, Phys. Fluids 5, No. 9, 1121-1122 (Sept. 1962).

The presence of electrons ahead of shockwaves, produced by exploding wires, has been detected by microwave absorption in argon, helium, nitrogen and air. Operating pressures have ranged from 1 to 50 centimeters of mercury. Electron densities of the order of $10^{12} \mathrm{~cm}^{-3}$ have been observed several centimeters ahead of the shock front.

The thermal conductivity of solid nitrogen, H. M. Roder, Letter to Editor Cryogenics 2, No. 5, 302-304 (Sept. 1962). The thermal conductivity of solid nitrogen from $4^{\circ}$ to about $28{ }^{\circ} \mathrm{K}$ was measured in an apparatus designed for detecting the effect of nitrogen free radicals, $\mathrm{N}^{*}$, trapped in the solid. The thickness of the sample was calculated from capacitance measurements assuming the dielectric constant to be given by the Clausius-Mossotti equation. Use of the capacitance method was justified by vertification of the Clausius-Mossotti equation down to $4^{\circ} \mathrm{K}$.

High pressure transition in RbF, G. Piermarini and C. E. Weir, J. Chem. Phys. 37, No. 8, $1887-1888$ (Oct. 15, 1962). X-ray diffraction data on $\mathrm{RbF}$ show that at high pressures the face centered cubic $\mathrm{NaCl}$ type structure is transformed to the simple cubic $\mathrm{CsCl}$ structure. The pressure is estimated to be between 9 and $15 \mathrm{~kb}$. The f.c.c. unit cell parameter of $5.64 \AA$ changes to a value of $3.27 \AA$ in the s.c. form. No alkali fluoride has been previously observed to undergo a transition under pressure.
Absorption bands of carbon dioxide from 2.8 to $4.2 \mu$, E. K. Plyler, E. D. Tidwell, and W. S. Benedict, J. Opt. Soc. Am. 52, No. 9, 1017-1022 (Sept. 1962).

The high-resolution spectrum of $\mathrm{CO}_{2}$ has been studied between 2.8 to $4.2 \mu$, using up to 48 meter-atmospheres path to develop weak bands. Accurate band constants have been obtained for the transitions $13^{1} 0-000,05^{1} 0-000$, and $101-02^{0} 0$, and fragments of new weak bands have been detected near $3500 \mathrm{~cm}^{-1}$. Estimates of band intensities are given, including a discussion of the highly abnormal intensity distribution in the weak perpendicular bands.

Synthesis of higher ketoses by aldol reactions. I. Three D-heptuloses, R. Schaffer and H. S. Isbell, Org. Chem. 2\%, 3268-3270 (Mar. 1962).

The 5,7-0-ethylidene acetals of D-altro, D-manno-, and D-glucoheptulose have been prepared directly from reaction of 2,4-0-ethylidene-D-erythrose with 1,3-dihydroxy-2-propanone. The ethylidene acetals of D-altro-heptulose and D-mannoheptulose were separated and isolated in crystalline form. The product having the D-gluco configuration was hydrolyzed to crystalline D-gluco-heptulose. The over-all yield of crystalline products was 44.5 percent. The synthesis demonstrates the utility of aldehydo-aldoses (having alkali-stable substituents) for the preparation of higher ketoses by the aldol synthesis.

Complex formation of monomeric amides with lithium perchlorate, A. F. Diorio, E. Lippincott, and I. Mandelkern, Nature 194, No. 4848, 1296-1297 (Sept. 1962).

The interaction of anhydrous lithium perchlorate with $N$-methylpropionamide was investigated by means of an infrared spectroscopic technique in order to elucidate the nature of the interaction of lithium salts with the peptide linkage of protein systems.

Upon addition of $\mathrm{LiClO}_{4}$, the amide I absorption band attributed to $\mathrm{C}=\mathrm{O}$ stretch is lowered in wave number; the single bond observed with the pure amide becomes a doublet. The strong band at $3300 \mathrm{~cm}^{-1}$ attributed to the $\mathrm{N}-\mathrm{H}$ stretching mode is completely replaced by a strong band at $3400 \mathrm{~cm}^{-1}$

It is concluded that the lithium ion interacts with the carbonyl group directly, with a disruption of the hydrogen bonded network of the pure liquid amide. These results indicate that the disruption of the ordered structure observed in protein systems could be a result of a similar binding phenomenon not involving water.

The thermodynamic temperature scale, Its definition and realization, C. M. Herzfeld, Book, Temperature, Its Measurement and Control in Science and Industry III, Pt. I, 41-50 (Reinhold Publ. Co., New York, N.Y., 1962).

A temperature scale based on thermodynamics is conceptually straightforward. The usual definition is given, and the realization of the scale by means of gas thermometry is discussed. The scale can be extended by appeal to the statistical mechanical interpretation of thermodynamics. Ways of doing this for high and low temperatures, using radiation and magnetic methods respectively, are presented.

Statistical mechanical arguments make possible the use of the concept of temperature for systems differing greatly from those contemplated in classical thermodynamics.

The thermodynamic scale of temperature below $1{ }^{\circ} \mathbf{K}, \mathrm{R}$. P. Hudson, Book, Temperature, Its Measurement and Control in Science and Industry 3, Pt. I, 51-57 (Reinhold Publ. Co., New York, N.Y., 1962).

Followinæ a brief discussion of the principles of magnetic thermometry, a description is given of the main methods used to derive the relation between the "magnetic scale" and the absolute scale of temperature. Experimental results published since 1953 are summarized. An account is given of the measurement of absolute temperature using the anisotropy of radiation emitted from oriented radioactive nuclei. Recent work on the intercomparison of "nuclear orientation scales," and on the comparison of one such scale with a magnetic scale, is reviewed. There follows a short account of the adaptation of the magnetic cooling method to nuclear paramagnetics and the production of temperatures of the order of one microdegree Kelvin. 
Hyperfine structure and intercombination line intensities in the spectra of magnesium, zinc, cadmium, and mercury, R. H. Garstang, J. Opt. Soc. Am. 52, No. 8, 845-851 (Aug. 1962). The transition probabilities of the lines $1_{\mathrm{s}_{0}}=3_{\mathrm{P}_{0}}$ and $1_{\mathrm{s}_{0}}=3_{\mathrm{P}_{2}}$ of the $\mathrm{s}^{2}=\mathrm{sp}$ arrays in $\mathrm{Mg} \mathrm{I}, \mathrm{Zn} \mathrm{I}, \mathrm{Cd} \mathrm{I}$ and $\mathrm{Hg} \mathrm{I}$, which arise by the interactions of the nuclear moments with the electrons, are computed for each odd isotope individually and for the naturally occurring isotopic mixture. The individual hyperfine structure component transition probabilities are given for the $1_{\mathrm{S}_{0}}-3_{\mathrm{P}_{2}}$ lines. Part of the intensity of the lines arises from the interaction of $3_{\mathrm{P}_{0}}$ or $3_{\mathrm{P}_{2}}$ with $3_{\mathrm{P}_{1}}$ and part from the interaction of $3_{\mathrm{P}_{0}}$ or $3_{\mathrm{P}_{2}}$ with $1_{\mathrm{P}_{1}}$, the former being more important for $1_{\mathrm{S}_{0}}-3_{\mathrm{P}_{0}}$ and the latter for $1_{\mathrm{s}_{0}}-3_{\mathrm{P}_{2}}$. Spin-spin and spin-other-orbit interactions in $\mathrm{Mg} \mathrm{I}$ are calculated for the $3 \mathrm{~s} 3 \mathrm{p}^{3} \mathrm{P}$ term and compared with observations.

Nuclear photoeffect in deformed nuclei, E. Hayward, Rendiconti Della Scuola Intern. Fisica "Enrico Fermi" XV,214-222 (Academic Press Inc., New York, N.Y., 1962).

The relationships between the total absorption and scattering cross sections for spherical and deformed nuclei are discussed. Recent results obtained using targets of holmium and erbium are presented.

Relaxation of nonequilibrium distributions, K. E. Shuler, Book, Temperature, Its Measurement and Control in Science and Industry III, Pt. 1, 27-34 (Reinhold Publ. Corp., New York, N.Y., 1962)

A review is presented of the relaxation of nonequilibrium distributions through interactions with a heat bath. As a specific example, the relaxation of an ensemble of harmonic oscillators has been considered in some detail.

Interpretation of rate experiments with resolved quantum levels, T. Carrington, Discussions Faraday Soc., No. 33, $44-51$ (1962).

It is now possible to study the steady state flourescence and chemiluminescence of small molecules in resolved quantum levels, and in other experiments to observe the time history of the vibfational or rotational relaxation of molecules suddenly produced in a non-equilibrium distribution. These experiments require interpretation in terms of rates or probabilities of vibrational or rotational energy exchange involving specified quantum states. If it is assumed that the state of a molecule after a collision depends only on its state immediately before the collision, and not on its previous history, or on the time at which the collision occurs, the sequence of collisions suffered by one molecule becomes a Markov chain and the appropriate mathematical formalism may be directly applied. This establishes a relationship between the observable transition rates and the more abstract concept of probability of transition per collision. The mathematical results are illustrated in discussing certain experiments.

\section{Other NBS Publications}

J. Research NBS 67C (Eng. and Instr.), No. 2 (Apr.-June 1963), 75 cents.

Temperature dependence of the elastic constants of thoric specimens of varying porosity. S. Spinner, L. Stone, and F. P. Knudsen.

Residual stresses and their relaxation on the surfaces of sections cut from plastically deformed steel specimens. C. J. Newton.

Permeation rates of electrolytic hydrogen and deuterium through iron. J. W. Pitts.

Steady state heat conduction in cylinders with multiple continuous line heat sources. B. A. Peavy.

A radial-flow apparatus for determining the thermal conductivity of loose-fill insulations to high temperatures. D. R. Flynn.

Analysis of a microwave radiometer for precise standardization of noise sources. G. D. Ward and J. M. Richardson.

Realistic evaluation of the precision and accuracy of instrument calibration systems. C. Eisenhart.
J. Research NBS 67D (Radio Prop.), No. 3 (May-June 1963), 70 cents.

Effects of radio wave propagation through mid-latitude 6300 A ares. J. R. Roach.

Comparison of observed atmospheric radio refraction effects with values predicted through the use of surface weather observations. B. R. Bean and G. D. Thayer.

Ionospheric scattering effects in long-distance propagation. H. A. Whale.

Concerning solutions of the VLF mode problem for an anisotropic curved ionosphere. J. R. Wait.

On the statistical theory of electromagnetic waves in a fluctuating medium (1). K. Furutsu.

Reception of skywave signals near a coastline. J. B. Andersen.

Analysis and synthesis of nonuniform transmission lines or stratified layers. G. Latmiral, G. Franceschetti, and R. Vinciguerra.

Resonant characteristics of a corrugated sphere. J. R. Wait and C. M. Jackson.

Impedances of long antennas in air and in dissipative media. D. W. Gooch, C. W. Harrison, Jr., R. W. P. King, and T. T. Wu.

Reflection of VLF radio waves from an inhomogeneous ionosphere. Part I. Exponentially varying isotropic model. J. R. Wait and L. C. Walters.

NBS viscometer calibrating liquids and capillary tube viscometers, R. C. Hardy, NBS Mono. 55 (Dec. 26, 1962), 20 cents.

Handbook for CRPL Ionospheric Predictions Based on Numerical Methods of Mapping, S. M. Ostrow, NBS Handb. 90 (Dec. 21, 1962), 40 cents (Supersedes Circ. 465).

1962 Research Highlights of the National Bureau of Standards, Annual Report, NBS Misc. Publ. 246 (Dec. 1962) 70 cents.

Equipment characteristics and their relation to system performance for tropospheric communication circuits, A. F. Barghausen, F. O. Guiraud, R. E. McGavin, S. Murahata, and R. W. Wilber, NBS Tech. Note 103 (Jan. 15, 1963), $\$ 1.00$.

A tabulation of the thermodynamic properties of normal hydrogen from low temperature to $300{ }^{\circ} \mathrm{K}$ and from 1 to 100 atmospheres, J. W. Dean, NBS Tech. Note 120 (Nov. 1961), 45 cents.

The thermodynamic properties of nitrogen from 114 to $540{ }^{\circ} \mathrm{R}$ between 1.0 and 3000 psia, Supplement A (British units), T. R. Strobridge, NBS Tech. Note 129A (Feb. 1963), 50 cents.

Coordinated color identifications for industry, K. L. Kelly, NBS Tech. Note 152 (Nov. 1962), 15 cents.

Thermal balance in the $\mathrm{F}$ region of the atmosphere, D. C. Hunt, NBS Tech. Note 162 (Sept. 1962), 50 cents.

Fading correlation bandwidth and short-term frequency stability measurements on a high-frequency transauroral path, J. L. Auterman, NBS Tech. Note 165 (Oct. 1962), 40 cents.

Ranking laboratories by round-robin tests, W. J. Youden, Mater. Res. Std. 3, No. 1, 9-13 (Jan. 1963).

The error rate in a multiple-frequency-shift system and the output signal/noise ratio in a frequency modulation and a pulse-code-modulation/frequency-shift system, H. Akima, Intern. Conf. Satellite Communication p. 305-310 (Nov. $22-28,1962)$.

Technical training in the weights and measures program, M. W. Jensen, Scale J. 49, No. 4, 4-5 (Jan. 1963) ; Southern Weights and Measures Program 14, No. 12, 2-5 (Dec. 1962).

Corrosion rates of ferrous alloys ( $\mathrm{Fe}, \mathrm{Cr}$, and $\mathrm{Fe}-\mathrm{Cr}-\mathrm{Si}$ ) measursd by polarization techniques, W. J. Schwerdtfeger, Corrosion 19, No. 1, 17t-25t (Jan. 1963).

A differential thermocouple voltmeter, J. E. Griffin and F. L. Hermach, AIEE Trans., Pt. I. Communications and Electronics No. 63, Article No. 62-819, 338-344 (Nov. 1962).

Color tests for antioxidants, E. J. Parks, L. T. Milliken, and F. J. Linnig, Rubber Age 92, No. 2, 257-261 (Nov. 1962). 
Cavitation problems in cyrogenics, R. B. Jacobs and K. B. Martin, J. Basic Eng. 82, 756-757 (Sept. 1960).

Airglow research in the United States, F. E. Roach, (Triennium Report of U.S. Natl. Comm. IUGG) Trans. Am. Geophys. Union 41, No. 2, 242-243 (1960).

The text revision of the international temperature scale of 1948, H. F. Stimson, Book, Temperature, Its Measurement and Control in Science and Industry 3, Pt. 1, 59-66 (Reinhold Publ. Corp., New York, N.Y., 1962).

Analysis of rotation errors of a waveguide theory vane antennuator, W. Larson, IRE Intern. Conv. Record, Pt 3, 213-219 (1962)

Survey of U.S.A. ionospheric research 1957-1959, T. N.

Gautier (Triennium Report of U.S. Natl. Comm. IUGG), Trans. Am. Geophys. Union 41, No. 2, 232-236 (June 1960)

On the analysis of polarization rotation recordings of satellite radio signals, R. S. Lawrence and C. G. Little, Intern. Sci. Radio Union, IGY Comm. Some Ionospheric Results Obtained During th IGY; Proc. Symp. Organized by URSI/AGI Comm. Brussels, Belgium, p. 392-399 (Elsvier Publ. Co., Amsterdam, The Netherlands, 1960)

Widely separated clocks with microsecond synchronization and independent distribution system, T. L. Davis and R. H. Doherty, IRE WESCON Conv. Pt. 5, p. 3-17 (1960).

Memorial to Sir Ronald Aylmer Fisher: 1890-1962, W. J. Youden, J. Am. Stat. Assoc. 57, No. 300, 727-728 (Dec. 1962).

A low impedance Maxwell bridge for measuring toroidallyshaped magnetic materials from 1 Kc to $100 \mathrm{Kc}, \mathrm{A}$. L. Rasmussen and R. C. Powell, Proc. IRE 50, 2505-2506 (Dec. 1962)

Radio properties of aurorae, C. G. Little, U.S.A. Natl. Comm. Intern. Sci. Radio Union Report to Natl. Acad. Sci.-Natl. Res. Council on 13th Gen. Assembly, Sept. 5-15, 1960, London, England, p. 216-270 (Natl. Acad. Sci.Natl. Res. Council, Washington, D.C., 1961).

Electrophoretic deposits of barium titanate, V. A. Lamb and V. A. Lamb and H. I. Salmon, Am. Ceram. Soc. 41, No. 11, 781-782 (Nov. 1962)

A rapid method of estimating the order of chemical reactions, J. H. Flynn, Chem. Eng. 69, 137-140 (Aug. 1962)

Tests for contingency tables and Markov chains, S. Kullback, M. Kupperman and H. H. Ku, Technometrics 4, No. 4, 573-608 (Nov. 1962).

Comments on the limits to the refractive index at ground level as a radio-meteorological parameter, B. R. Bean and G. D. Thayer, Proc. IRE 48, No. 8, 1498-1501 (Aug. 1960).

Energy exchange in the biosphere, D. M. Gates, Book, Harper \& Row Publ., New York, N.Y., 1962.

On the propagation of ELF pulses in the earth-ionosphere waveguide, J. R. Wait, Can. J. Phys. 40, 1360-1369 (Oct. 1962).

Interpretation of $p \mathrm{H}$ measurements in alcohol-water solvents, R. G. Bates and R. A. Robinson, Proc. 7th Intern. Conf. Coordination Chemistry, Stockholm, Sweden, p. 342-344 (1962).

Polymorphism in fibrous polypeptides: $\alpha \rightleftarrows \beta$ transformation in naturally occurring keratin, A. F. Diorio, L. Mandelkern, and E. R. Lippincott, J. Phys. Chem. 66, No. 11, 2096-2100 (Nov. 1962).

Recent radar observations of new forms of ionosphere scatter, K. L. Bowles, U.S.A. Natl. Comm. Intern. Sci. Radio Union Report to Natl. Acad. Sci.-Natl. Res. Council on 13th Gen. Assembly, Sept. 5-15, 1960, London, England, p. 288-295 (Natl. Acad. Sci.-Natl. Res. Council, Washington., D.C., 1961).

The significance of transients and steady-state behavior in nonlinear systems, W. J. Hartman, Proc. IRE Correspondence Section 49, No. 3, 637 (Mar. 1961).

Photoionization from outer atomic subshells. A model study, J. W. Cooper, Phys. Rev. 128, No. 2, 681-693 (Oct. 15, 1962).

Solar flare effects in the $F$-region of the ionosphere, R. W. Knecht and R. E. McDuffie (Proc. Intern. Conf. Cosmic Rays and the Earth Storm), J. Phys. Soc. Japan 17, Suppl. A, Pt. I, 280-285 (1962).

Recent experiments on liquid helium vapor pressure measure- ments from $2^{\circ}$ to $4^{\circ}$ K, G. Cataland, M. H. Edlow, and H. H. Plumb, Book, Temperature, Its Measurement and Control in Science and Industry 3, Pt. 1, 413-417 (Reinhold Publ. Corp., New York, N.Y., 1962).

Low-level low-frequency detection system, N. T. Larsen, Rev. Sei. Instr. 33, 1200-1208 (Nov. 1962).

On the extension of the low-chromosphere model to the region of origin of the UV solar spectrum, R. N. Thomas, (Proc. 10th Astrophysical Symp. Liege, Belgium), Mem. Roy. Soc. Belgium 20, 305 (1961).

Very-low-frequency phase observations on the ionospheric effects of the solar flare of September 28, 1961, A. G. Jean and J. H. Crary, J. Geophys. Reas. 67, No. 12, 4903-4905 (Nov. 1962)

The radiant energy from sources in the far infrared, $\mathrm{E}, \mathrm{K}$. Plyer, D. Yates, and H. A. Gebbie, J. Opt. Soc. Am. 5\%, No. 8, 859-861 (Aug. 1962).

Obtaining the internal junction characteristics of a transistor for use in analog simulation, S. B. Geller, IRE Trans. Electron. Computers EC-11, No. 5, 709-710 (Oct. 1962).

Graphical evaluation of analytical results, W. J. Youden, Proc. Conf. Chemical Control Problems, p. 1-15 (Spon. Natl. Plant Food Inst., Washington, D.C., 1959).

The measurement of ionospheric drifts by means of a Doppler technique, K. Davies, J. Geophys. Res. 6z, No. 12, 49094913 (Nov. 1962).

Laboratory astrophysics, L. M. Branscomb and R. N. Thomas Phys. Today 15, 42-44, 46 (Nov. 1962).

Standards - The key to success in engineering, A. T McPherson, Rev. Centro Estud. Ing. 130, No. 656, 352-35. (1961)

Precision phase meter, D. M. Waters, D. Smith, and M. C. Thompson, Jr., IRE Trans. Instr. I-II, 64-66 (Sept. 1962).

The effect of temperature and humidity on the oxidation of air-blown asphalts, P. G. Campbell, J. R. Wright, and P. B. Bowman, Mater. Res. Std. 2, No. 12, 988-995 (Dec. 1962).

Standards for the future, R. D. Huntoon, Proc. Annual Spring Conf. Standards Engineers Society, Boston Section and Company Member Conf. of American Standards Association, May 24-25, 1962 (Boston, Mass., 1962).

Intramolecular rearrangements in the solid phase photolysis of 4-methyl-2-hexanone and sec-butyl acetate, R. E. Rebbert and P. Ausloos, J. Chem. Phys. 37, No. 5, 1158-1159 (Sept. $1,1962)$.

The vapor phase fluorescence and its relationship to the photolysis of propionaldehyde and the butyraldehydes, R. P. Borkowsik and P. Ausloos, J. Am. Chem. Soc. 84, No. 21, 4044-4048 (Nov. 1962)

Crosslinking of polymers induced by excited species, L. A. Wall and R. B. Ingalls, J. Polvmer Sci. Letter to Editor 62, No. 173 , S5-S6 (1962)

Standard electromotive force of the cell $\mathrm{H}_{2} ; \mathrm{HBr}(\mathrm{m}) ; \mathrm{AgBr}$; $\mathrm{Ag}$ from 0 to $50^{\circ}, \mathrm{H}$. B. Hetzer, R. A. Robinson, and R. G. Bates, J. Phys. Chem. 66, No. 8, 1423-1426 (1962). Vacuum ultraviolet photochemistry. IV. Photolysis of propane, H. Okabe and J. R. MeNesby, J. Chem. Phys. 37, No. 6, 1340-1346 (Sept 1962).

Conformation and frictional properties of polystyrene in dilute solutions, D. MeIntyre, A. Wims, L. C. Williams, and L Mandelkern, J. Phys. Chem. 66, 1932-1940 (Oct. 1962).

Use of a "peek-a-boo" information retrieval technique for a personal reference file, J. A. Bennett, J. Wash. Acad. Sci. 52, No. 9, 216-219 (Dec. 1962).

Photographic strain measuring technique for use above 3,000 F, L. Mordfin and T. Rubusto, Jr., Proc. Instr. Soc. Am. 17, Pt. 1, 3.4.62-1 (1962).

The speed of processes involved in electroplating: movement of solute, attainment of the steady state and formation of metal, A. Brenner, 49th Annual Tech. Proc. Am. Electroplaters Soc. p. 9-13 (1962).

* Publications for which a price is indicated may be obtained from the Superintendent of Documents, U.S. Government Printing Office, Washington 25, D.C. (foreign postage onefourth additional). Reprints from outside journals and the NBS Journal of Research may often be obtained from the authors. 